\title{
Antihypertensive drugs in pregnancy
}

\author{
Rose Gasnier ${ }^{1}$, Edimárlei Gonsales VAlÉrio², José Geraldo lopes Ramos³
}

\begin{abstract}
Chronic hypertension complicates 3\%-5\% of pregnancies and gestational hypertension occurs in $6 \%$ of pregnancies. Preeclampsia complicates $25 \%$ of the pregnancies with chronic hypertension, and approximately $15 \%-45 \%$ of the patients with gestational hypertension will develop preeclampsia, a dangerous condition that harms the maternal and fetal safety. Antihypertensive medication is used to treat severe hypertension to prevent serious maternal and fetal complications, but there is no consensus on when and how to treat mild-to-moderate hypertension in pregnancy. This article reviews the usage, effect and safety of first, second and third line antihypertensive drugs for mild-tomoderate hypertension in pregnancy.
\end{abstract}

Keywords: Gestational hypertension, Mild-to-moderate hypertension, Antihypertensive drugs

\section{Hypertension in pregnancy}

For the hypertension diagnosis, blood pressure (BP) must be elevated on at least two occasions and measurements should be made with the woman seated and using the appropriate cuff size. Late in the second trimester and the third trimester, venous return may be obstructed by the gravid uterus and, if supine, blood pressure should be taken with the woman lying on her side. Chronic hypertension is diagnosed before pregnancy or in the first 20 weeks of gestation, or persists more than 42 days after delivery, complicating $3 \%-5 \%$ of pregnancies [1]. In gestational hypertension, occurring in $6 \%$ of pregnancies, blood pressure is established after the week 20 of pregnancy, and is not associated to proteinuria or other systemic features of preeclampsia, with normalization during the 12 weeks following delivery. Approximately $15 \%-45 \%$ of the patients with gestational hypertension will develop preeclampsia, and is more likely with earlier presentation, previous hypertensive pregnancy and higher blood pressure $[2,3]$. The effect of antihypertensive drugs is different in these conditions, which must be considered when interpreting randomized trials of the treatment of hypertension in pregnancy. Preeclampsia is more dangerous than chronic hypertension and gestational hypertension, and is characterized by hypertension and proteinuria (0.3 g/24 hours). Eclampsia is described as the appearance of convulsions associated with the signs of preeclampsia, and not caused by epilepsy or other convulsive disorders. Preeclampsia superimposed on chronic hypertension is defined as a condition of hypertension with onset of proteinuria, complicating $25 \%$ of the pregnancies with chronic hypertension [4].

\section{Physiological adaptations in pregnancy} and hypertension

Early in the first trimester there is a fall in
1 Post Graduate Program in Medicine, Universidade Federal do Rio Grande do Sul, Hospital de Clínicas de Porto Alegre, Brazil

2Service of Obstetrician and Gynecology, Hospital de Clínicas de Porto Alegre, Brazil 3Service of Obstetrician and Gynecology, Hospital de Clínicas de Porto Alegre, Brazil; Universidade Federal do Rio Grande do Sul, Porto Alegre, Brazil

CORRESPONDING AUTHOR: Rose Gasnier

Universidade Federal do Rio Grande do Sul, Hospital de Clínicas de Porto Alegre, Brazil gasnier.rose@gmail.com

Funding: This research received no specific grant from any funding agency in the public, commercial, or not-for-profit sectors. 
blood pressure caused by active vasodilatation through local mediators. This reduction primarily affects the diastolic pressure and a drop of $10 \mathrm{~mm} \mathrm{Hg}$ is usual by 13-20 weeks of gestation. Blood pressure continues to fall until 2224 weeks when a nadir is reached. After this, there is a gradual increase in blood pressure until a term when pre-pregnancy levels are attained. Immediately after delivery blood pressure usually falls, then increases over the first five postpartum days. Even women whose blood pressure was normal during pregnancy may experience transient hypertension in the early postpartum period, reflecting a degree of vasomotor instability $[5,6]$.

Secondary to the reduction in the systemic vascular resistance, chronic hypertension often improves in the second trimester and early third trimester, to be restored in late pregnancy. Patients with essential hypertension stage I (BP 140159/90-99 mmHg) without target organ damage have an excellent prognosis in pregnancy. Women with chronic hypertension have a $10 \%$ to $30 \%$ increased risk of developing preeclampsia [7]. If preeclampsia does not occur, the course of mild and moderate essential hypertension is benign, and it is uncertain whether antihypertensive treatment improves the outcome of pregnancy. Prevention of preeclampsia is desirable, but either specific BP targets or antihypertensive agents modify the risk [8]. The hypertension of preeclampsia is secondary to placental under perfusion: lowering systemic BP is not believed to reverse the primary pathogenic process. Some women with gestational hypertension remain hypertensive after delivery. They most likely have preexisting chronic hypertension masked in early pregnancy by physiological vasodilatation.

Preeclampsia is a progressive systemic disease due to inadequate trophoblastic invasion of the spiral arterioles that occurs in 5\%-8\% of all pregnancies. It is associated with significant maternal and fetal morbidity and mortality. In preeclampsia hypertension is due to generalized arteriolar vasospasm and decreased plasma volume. The spiral arteries of the placenta maintain their responsiveness to vasoactive substances. Altered prostanoid metabolism and nitric oxide production in placental blood vessels also occurs. The pathological processes in the placenta result in dissemination of abnormal substances throughout the circulation, leading to disturbed endothelial function with multi-organ system clinical features, platelet consumption, increased vascular resistance, and hypertension [9].

Fetal growth restriction secondary to placental insufficiency commonly occurs in pregnancies complicated by hypertension. Any reduction in maternal blood pressure may be accompanied by a decrease in uterine perfusion pressure which may diminish uterine blood flow and fetal oxygen supply. This effect may be exacerbated with decreased blood volume, as occurs in preeclampsia. Dilatation of the uterine arteries may also reduce the critical perfusion pressure necessary for an adequate supply of oxygen to the fetus.

\section{Treatment of hypertension}

The control of severe hypertension is uncontroversial. It is well proven that mean arterial pressure $(\mathrm{MAP})>140 \mathrm{~mm}$ $\mathrm{Hg}$ can result in cerebral arteriolar damage. Histological changes are detectable as early as 10 minutes after the onset of severe hypertension, and clinically apparent arteriolar damage is seen within a few hours. Cerebral hemorrhage is the commonest cause of maternal death in preeclampsia and eclampsia. While severe hypertension (SBP $170 \mathrm{~mm} \mathrm{Hg}$ and/or DBP $110 \mathrm{~mm} \mathrm{Hg}$ ) in pregnancy represents a very serious risk for maternal health, mild-to-moderate hypertension (BP from 140/90 to $169 / 109 \mathrm{~mm}$ $\mathrm{Hg}$, as classified by NHBPEP) [10] in pregnancy is associated with lower maternal risk [8]. Those with hypertensive encephalopathy, hemorrhage or eclampsia require treatment with parenteral agents to lower mean arterial pressure by $25 \%$ over minutes to hours and then to further lower BP to $160 / 100 \mathrm{~mm} \mathrm{Hg}$ over subsequent hours [10], avoiding hypotension because of fetal distress. Lower doses should be initiated in preeclampsia, because of volume depletion.

The question has been raised whether treatment is necessary in mildto-moderate hypertension (DBP 90-100 $\mathrm{mm} \mathrm{Hg}$ ), especially in the absence of proteinuria [11]. It is not clear in clinical practice when to use antihypertensive drugs and what level of BP to target during pregnancy: selection of patients, choice of drug and duration of pregnancy at the beginning of treatment may be of great importance. The rapidity of the increase in blood pressure may be more important than the actual level of the blood pressure. Sibai considers that women with mild, uncomplicated chronic hypertension will accomplish good 
perinatal outcome regardless of the use of antihypertensive therapy [12]. Clinical trials indicate non-consistent data concerning antihypertensive treatment on antenatal rate of hospitalization, proteinuria at delivery and neonatal respiratory distress syndrome, preeclampsia, fetal neonatal death, preterm labor or intra-uterine growth restriction (IUGR) $[13,14]$.

Women with chronic hypertension should be evaluated before conception or at time of first prenatal care visit, and divided into categories of high and low risk. High risk women should receive aggressive antihypertensive treatment and frequent evaluations of maternal and fetal well-being, and doctors should recommend lifestyle changes. These women are at increased risk of post partum complications as pulmonary edema, renal failure and hypertensive encephalopathy for which they should receive aggressive control of blood pressure as well as close monitoring. In women with low risk (essential uncomplicated) chronic hypertension, antihypertensive agents are used despite absent evidence of either benefits or harm from this therapy, based on consensus rather than scientific evidence $[4,15]$.

Chronic hypertension therapy can be stopped during pregnancy under close observation, or a woman whose arterial pressure is well controlled by antihypertensive drugs before pregnancy may continue with the same agents, if not contraindicated. The National Institutes of Health - sponsored Working Group on High Blood Pressure in Pregnancy recommend antihypertensive therapy for blood pressures exceeding a threshold of
150 to $160 \mathrm{~mm} \mathrm{Hg}$ systolic or 100 to 110 $\mathrm{mm} \mathrm{Hg}$ diastolic or in the presence of target organ damage $[1,10]$. The focus of treatment is the pregnancy, during which untreated mild-to-moderate hypertension is likely to lead to unfavorable long-term maternal outcomes. The drugs used are mainly to prevent and treat severe hypertension, with the objective of prolonging pregnancy for as long as safely possible, thereby maximizing the gestational age and to minimize fetal exposure to medications that may have adverse effects. In a review of the Cochrane Pregnancy and Childbirth Group Trials Register, until better evidence is available, the choice of antihypertensive should depend on the clinician's experience and familiarity with a particular drug and on what is known about adverse effects [16].

Benefits and risks of antihypertensive treatment for mild-to-moderate hypertension are not completely defined in recent reviews, including a Cochrane meta-analysis $[8,17]$. It appears that with the use of antihypertensive treatment, there is less risk of developing severe hypertension, but no difference in outcomes of preeclampsia, neonatal death, preterm birth, and small-for-gestationalage (SGA) infants. Some investigators concluded that women with mild hypertension do not need antihypertensive treatment if they are closely followed up during pregnancy and delivery, especially pregnant women without hypertension and proteinuria development before pregnancy. For women with chronic hypertension and mild-to-moderate hypertension before pregnancy, without target organ damage, clinicians can consider discontinuing antihypertensive treatment and monitoring. Therapy can be initiated if the BP again rises to 140-150/90-100 $\mathrm{mm} \mathrm{Hg} \mathrm{[18].} \mathrm{In} \mathrm{women} \mathrm{with} \mathrm{renal} \mathrm{dys-}$ function, it may be reasonable to choose a slightly lower threshold for treatment [4].

Doubts concerning antihypertensive drugs use in pregnancy mostly refer to the effects they might have on the developing fetus. Antihypertensive agents cross the placental barrier and are present in various concentrations in the fetal circulation. It was noticed that the incident of SGA infants and reduction of birth weight were increased with higher antihypertensive-induced fall in mean arterial BP among women who took antihypertensive drugs when BP reached 160/110 mm Hg. Among women whose BP was normalized (DBP $<90 \mathrm{~mm}$ $\mathrm{Hg}$ ), there was a decrease in the risk of severe hypertension, maternal hospitalization and proteinuria at delivery [19]. Antihypertensive treatments for mild-tomoderate hypertension are beneficial for the mother, but pregnancy outcome has been found to be similar or even worse $[8,17]$.

International societies have differed in their attitudes and recommendations for the BP which should initiate antihypertensive therapy. The U.S. professional bodies recommend starting with the therapy at BP $160 / 105 \mathrm{~mm} \mathrm{Hg}$, not defining the target values [10]. The Canadian Hypertension Society recommends normalization of BP for most disorders with BP of 140-150/90-95 mm $\mathrm{Hg}$, targeting DBP of 80-89 mm Hg [20]. The Australian professional bodies recommend initiation of antihypertensive treatment at BP 160/90 mm Hg and con- 
ducting therapy to the BP value of 110 140/80-90 mm Hg [21].

There are still no definitive and complete data about safe BP treatment targets for women with hypertension in pregnancy, however guidelines and reviews generally recommend the introduction of antihypertensive treatment with the BP values of 140-155/90-105 $\mathrm{mm} \mathrm{Hg}$ [22]. In contrast to hypertension guidelines in clinical practice, which emphasize the systolic BP, much of the obstetric literature focuses on diastolic BP, in part because of the lack of clinical trials to support one approach versus another. A recent review of women who suffered stroke in the setting of preeclampsia demonstrated systolic hypertension more prevalent than diastolic hypertension (most women did not reach DBP of $110 \mathrm{~mm} \mathrm{Hg}$ ) [23].

\section{Antihypertensive drugs}

One concern is that hypertension or iatrogenic hypotension might cause cardiovascular malformations by altering perfusion in the placenta and/or fetus [24]. Because of the circulating plasma volume contraction, women may be very sensitive to relatively small doses of antihypertensive agents, risking abrupt reductions in blood pressure. A population-based, case-control study, with data from the National Birth Defects Prevention Study, with 5,021 cases and 4,796 controls, concluded that antihypertensive medication use and/ or the underlying hypertension might increase the risk of having an infant with specific left and right obstructive and septal defects, but additional studies will be needed to confirm these findings
[25]. The FDA classifies the medications in pregnancy under one of five letter categories - A, B, C, D and X. This classification may reflect occasional lack of knowledge rather than actual proven harm. Practitioners may find themselves armed with data favoring the use of older and potentially safer medications over newer medications with possibly more approved indications.

During normal pregnancy maternal vascular and hemodynamic changes occur that have the potential to change the pharmacokinetics of drugs. Peripheral vascular resistance progressively falls in pregnancy, leading to a reduction in arterial pressure despite the increases in cardiac output, ventricular stroke volume and heart rate. The increase in maternal plasma volume leads to a progressive fall in plasma albumin concentration and plasma protein binding of certain drugs, and the volume of distribution of some medications is altered. The increase of renal plasma flow and glomerular filtration rate speeds up the clearance of drugs. Placental transfer of low molecular weight and lipid-soluble drugs is more efficient. The fetal concentrations equilibrate slowly with the maternal circulation. The changes in hemodynamic circulation return to normal in the postpartum period. Postpartum hypertension is common. Women who experience hypertension in pregnancy may be normotensive immediately after the birth, but then become hypertensive again.

\section{Centrally acting alfa-2-adrenergic} agonists

Methyldopa is the most frequently pre- scribed and the agent of first choice of treatment of hypertension in pregnancy. There is extensively experience with the drug and long-term follow-up data regarding children whose mothers received methyldopa during pregnancy with proven maternal and fetal safety $[22,26]$. In a follow-up study of a large clinical trial on the effectiveness of methyldopa versus no treatment, no differences were found in the functional development of children at 4 and 7.5 years of age [27,28]. During the long term treatment, the drug does not alter cardiac output or blood flow to the uterus or kidneys [29]. Also fetal heart rate patterns were not significantly changed during the treatment [30]. BP control is gradual, over 6 to 8 hours, because of the indirect mechanism of action. Based on the long history of use, it does not seem to be teratogenic. It was tested in several trials compared to placebo or other antihypertensive treatments. Treatment with methyldopa has been reported to prevent subsequent progression to severe hypertension in pregnancy and does not seem to have adverse effects on uteroplacental or fetal hemodynamics or on fetal wellbeing [31].

Adverse effects are consequence of central alfa-2-agonism or decreased peripheral sympathetic tone. These drugs act in sites in brain stem to decrease mental alertness and impair sleep, leading to fatigue, depression, and poor sleep. Decreasing salivation leading to xerostomia is experienced. Elevated transaminase (5\%), hepatitis and hepatic necrosis have also been reported. Some patients will develop a positive antinuclear antigen or antiglobulin (Coombs) 
test with chronic use and this is occasionally associated with clinical hemolytic anemia. In these cases, medications of other classes are used [32].

Clonidine, a selective alfa-2-agonist, acts similarly and is comparable to methyldopa with respect to safety and efficacy. Sleeping disturbances after prenatal exposure have been reported in a cohort study. It is used as third agent line for multidrug control of refractory hypertension [33].

\section{Peripherally acting adrenergic- receptor antagonists}

Beta-blockers have been used extensively in pregnancy. None of the betablockers have been associated with teratogenicity. Although several randomized trials have been conducted, there are still some unresolved issues regarding their use in pregnancy, a result of a few small studies that suggest an association with lower birth weight infants. Betablockers are still avoided in the first half of pregnancy because of concerns about growth restriction and are viewed as third line agents. Beta-blockers are safe throughout pregnancy and there is wide experience with oxprenolol and labetalol [33]. However, in a recent meta-analysis of published data from randomized trials, the presence of intrauterine growth retardation appeared not to be related to the antihypertensive used [34].

Labetalol blocks both alfa- and betaadrenoceptors, a non selective betablocker with vascular alfa1-receptorblocking effects, and produces its antihypotensive effects without compromising the maternal cardiovascular system, which is significant in maintaining renal and uterine blood flow. Its immediate and prolonged effect, the increase in uteroplacental flow and the rarity of maternal and fetal side effects lead to it being frequently used. In a trial where 263 patients with mild-to-moderate hypertension were randomly divided into methyldopa, labetalol and no treatment groups, patients with therapy had significantly lower maternal blood pressures compared to the non medication group and no differences were seen among the groups concerning gestational age at delivery, birth weight, incidence of fetal growth restriction, neonatal head circumference, or uteroplacental circulation [31].

This drug has gained wide acceptance in pregnancy. It is considered safe and effective treatment, although neonatal hypoglycemia has been reported with higher doses, and one placebo controlled study reported an association with fetal growth restriction in the management of preeclampsia remote from term [35]. It is used parentally to treat severe hypertension because of a lower incidence of maternal hypotension and other adverse effects. Its use now supplants that of hydralazine [36], which was previously the most commonly used agent for the treatment of severe hypertension. There is wide interpatient variability in the dose of labetalol required to control BP, an event that is not predictable by any clinical item before therapy. Another problem is the variable duration of action, particularly in patients who require higher doses. In addition, congestive heart failure, asthma, sinus bradycardia, and first-degree atrial-ventricular block contraindicate its use.
In some centers methyldopa was substituted for labetalol as the first choice of treatment because of central side effects of methyldopa. Currently both drugs are still being used for hypertension in pregnancy. Adverse effects may be predicted because of beta-receptor blockade. Lethargy, fatigue, exercise intolerance, peripheral vasoconstriction, sleep disturbance (with use of more lipide-soluble agents) and bronchoconstriction may appear, but discontinuation of usage because of adverse effects is uncommon [8]. In a historical cohort study to determine the functional development of children born after treatment of mildto-moderate hypertension with labetalol versus methyldopa, and no medication, labetalol exposure in utero seemed to increase the risk of attention deficit disorder (ADD) and possibly gross motor development among children of primary school age, whereas prenatal methyldopa exposure might influence sleep, but further studies are necessary [37]. The neurological dysfunction could be explained by small for gestational age effects. The drug could also affect blood flow through the placenta, as labetalol has been found to increase placental vascular resistance, whereas methyldopa decreases it. The fetal bradycardia induced by adrenergic blockade also could alter neurodevelopment outcome [1].

Atenolol is a commonly used cardio selective beta-blocker in non pregnant patients, but its use especially in early pregnancy should be avoided. Placebocontrolled study demonstrated that atenolol for chronic hypertension treatment in early pregnancy, mean 15.9 weeks of pregnancy, is associated with signifi- 
cantly lower birth weight and higher proportion of small-for-gestational age, as compared to the placebo group [19]. Bayliss concluded that low birth weight was associated with atenolol taken at the time of conception or during the first trimester of pregnancy [38]. Studies with atenolol in preeclampsia failed to find differences, maybe because of the late starting therapy. Atenolol should be avoided in early stages of pregnancy and given with caution at later stages, as it has been associated with fetal growth impairment and lower birth weights.

In a meta-analysis and Cochrane review in 2000, individual agents were not different in their perinatal effect with the exception of atenolol, which in one small study was started at 12 to 24 weeks and resulted in significant fetal growth restriction and decreased placental weight compared to placebo. These findings were supported in subsequent retrospective review comparing atenolol with alternative therapies [39]. Oral betablockers for mild-to-moderate hypertension during pregnancy have specifically been estimated in the Cochrane database [36]. Oral beta-blockers, except atenolol, decrease the risk of severe hypertension. It has been estimated that beta-blockers appear to be associated with an increase in small-for-gestational age infants and frequency of non clinical neonatal bradycardia, although in a systematic review of trials, labetalol does not (along with oral methyldopa, nifedipine or hydralazyne) seem to cause neonatal heart defects [40]. The respiratory distress syndrome and maternal hospital admissions decrease. Beta-blockers treatment seems to be no more effective compared with methyldopa. Parenteral therapy has been found to increase the risk of neonatal bradycardia, requiring intervention in 1 out of 6 newborns [1].

Maternal outcomes are improved with the use of beta-blockers, with effective control of BP, decreased incidence of severe hypertension, and decreased rate of preterm admission at hospital [1]. They have been found to be more effective in lowering BP compared with methyldopa in 10 trials in a recent $\mathrm{Co}-$ chrane analysis [8].

Peripherally acting alfa-adrenergic antagonists are second line antihypertensive drugs in non pregnant adults. These are indicated during pregnancy in the management of hypertension because of suspected pheochromocytoma, and both prazosin and phenoxybenzamine have been used, with beta-blockers used as adjunctive agents after alfa-blockade is accomplished [41]. Because there is limited experience with these drugs in pregnancy, their routine use cannot be advocated.

\section{Calcium channel antagonists}

Calcium channel antagonists have been used to treat chronic hypertension, mild preeclampsia presenting late in gestation and urgent hypertension associated with preeclampsia. The papers have focused on the use of nifedipine, although there are reports of nicardipine, isradipine, felodipine and verapamil [42-45]. Amlodipine has been used in pregnancy but safety data are lacking. Nifedipine is a dihydropyridine calcium channel blocker that is widely used for the treatment of cardiovascular disorders in non pregnant individuals. Over the last decades its favorable characteristics have resulted in its efficacy and safety being assessed in pregnancy. Its application both as a treatment for acute severe hypertension, as well as for long term use for hypertension in pregnancy, have been explored. This drug is a type 2 calcium channel blocker that inhibits the inward flow of calcium across the L-type slow channels of cellular membranes. It has minimal effect on the cardiac conducting system. It causes a decrease in arterial vascular resistance but with minimal effect on the venous system. It results in a $20 \%$ lowering of the systolic, diastolic and arterial blood pressures. An increase in cardiac output results from both reflex tachycardia secondary to stimulation of the sympathetic nervous system and an increase in stroke volume. Hepatic and renal blood flows are also increased. This vascular relaxation, which is marked in hypertensive patients, does not occur significantly in normotensive patients, thus allowing the drug to be used in its other applications.

Brown et al compared efficacy and safety of $10 \mathrm{mg}$ nifedipine tablets with rapid onset and short-acting $10 \mathrm{mg}$ nifedipine capsules for the treatment of severe hypertension in the second half of pregnancy [46]. Although slower at the start, nifedipine tablets were as effective as capsules for the rapid treatment of severe hypertension. Some other studies reported that administration of shortacting nifedipine capsules has been associated with maternal hypotension and fetal distress, which suggested the usage of a long acting preparation.

Maximum serum concentrations of the drug are obtained most quickly if 
the capsule is first bitten and the drug then swallowed. With standard oral administration the peak concentration occurs slightly later. Blood pressure falls within five to ten minutes of a capsule being bitten, and ten to thirty minutes with oral administration. Metabolism occurs in the liver, $30 \%$ to $40 \%$ of the drug being metabolized in the first pass, and the inactive metabolites are excreted in the urine. In pregnancy the physiological changes in the cardiovascular system and in hepatic function result in an increased rate of metabolism and clearance of the drug. Due to these differences in metabolism and clearance in pregnancy, the duration of action of nifedipine is reduced to four to six hours. Higher and more frequent doses are required in pregnant women to obtain adequate antihypertensive effects. The recommended starting dose is 10 to 20 $\mathrm{mg}$, one dose per six hours. The efficacy and safety of long acting oral nifedipine, with less risk of hypotension and fetal distress, was advocated its use for severe hypertension in pregnancy $[46,47]$. The mode of action of nifedipine to reduce systemic vascular resistance and its ability to improve urine output by increasing renal blood flow and by inhibiting the release of antidiuretic hormone make it a highly appropriate drug for treating hypertension in pregnancy [48]. If rapid BP control is desired, the use of parenteral labetalol or hydralazine is recommended, until the desired target is achieved. The Canadian Hypertension Society as well as the Australasian Society for Study of Hypertension has both recommended its use as one of the first line drugs in severe hypertension in pregnancy.

Concern has been raised about the concurrent use of magnesium sulphate and nifedipine and the possible neuromuscular blockade, myocardial depression and circulatory collapse. Although two drugs with negative inotropic action may not compromise in a woman with normal ventricular function, this may not be true in a woman with heart disease. In practice and in a recent evaluation, these medications are commonly used together without increased risk [49]. The additional antihypertensive effect when nifedipine is used with other antihypertensive agents as methyldopa and beta-blockers appears not to occur. Betaadrenergic blocking drugs may reduce the tachycardia induced by nifedipine. Nifedipine also causes an increase in blood flow to the liver which may alter the metabolism of other drugs, and had been shown to affect blood levels of digoxin and phenytoin.

Maternal side effects with nifedipine seldom occur, and there is rarely a need to stop the drug as a result of these. Side effects are related to the dose and include flushing, headaches, sweaty palms, peripheral edema [50]; rarely constipation, diarrhea, heartburn, dyspnea, and chest pain have been described. Tachycardia occurs commonly but is seldom associated with palpitations and appears to have no adverse effects.

Sibai studied 200 pregnant women between 26 to 36 weeks of gestation who were randomized to bed rest alone or bed rest plus nifedipine. Blood pressure was lower in patients who received nifedipine $(\mathrm{P}<0.0001)$. The difference between the groups in regard to birth weight, incidence of SGA, preterm birth and the number of days spent in the special care unit was not detected. Magee et al concluded that, according to a multicenter cohort, nifedipine and verapamil, which have been best studied, did not seem to pose teratogenic risks to fetuses exposed in the first trimester [51]. Nifedipine does not seem to cause decrease in uterine blood flow. A randomized, clinical, double blind and placebo controlled trial, whose objective was to observe if there was a uteroplacental and fetoplacental flow variation during its chronic use, did not find damage to the flow indices. Experimental studies did not found any significant alteration in uterine blood flow with nifedipine, despite a reduction in placental vascular resistance.

Nicardipine has a less negative inotropic effect than other calcium-entry blockers and evokes less reflex tachycardia because of its more selective effects on blood vessels than on the myocardium. It does not seem to accumulate in the plasma, membranes or umbilical circulation. Clinical studies with intravenous nicardipine in preeclampsia are scarce and often not controlled [52]. A randomized, prospective, controlled study on nicardipine versus labetalol for severe hypertension in pregnancy had shown that both drugs were effective and safe in the initial treatment [53].

Nifedipine has been compared with methyldopa for the treatment of pregnancy-induced hypertension and been shown to be comparable in its antihypertensive action but achieved no improvement in prolongation of pregnancy or fetal outcome. It appears to be as good 
as hydralazine in its antihypertensive effect, but its onset of action is less likely to be precipitous. Both drugs seem to reduce blood pressure to acceptable levels due to a significant reduction in systemic vascular resistance, accompanied by similar increases in cardiac output and heart rate. Pulmonary capillary wedge pressure decreases significantly less with nifedipine than with hydralazine. Nifedipine is also associated with fewer episodes of acute fetal distress, as suggested by non reassuring fetal heart rate changes in pregnancies with and without intrauterine growth restriction. Different units have their preferences for either parenteral labetalol or hydralazine, and some use oral nifedipine.

\section{Direct vasodilators}

Dihydralazine selectively relaxes arteriolar smooth muscle by an unknown mechanism. It has been commonly used in the acute emergency or as a third line agent for multidrug control of refractory hypertension, but its side effects of headache, nausea, flushing, palpitation and tachycardia, as well as its ability to cause too rapid a fall in blood pressure are well described, due to excessive vasodilatation or sympathetic activation. It is possible that these hypotensive episodes may be a reflection of underlying intravascular volume status rather than any property of the drug itself. Hydralazine should be given after a colloid challenge to reduce the reflex tachycardia and abrupt hypotension. Also oral hydralazine has been widely used for chronic hypertension in the second and third trimesters, but its use has been supplanted by agents with more favorable adverse effects [54]. Chronic use can lead in rare cases to a pyridoxine-responsive poly-neuropathy or to immunologic reactions, including a drug-induced lupus syndrome. It has been used in all trimesters of pregnancy, and data have not shown an association with teratogenicity, although neonatal thrombocytopenia and lupus have been reported [55].

A recent meta-analysis of intravenous hydralazine usage in severe hypertension in pregnancy concluded that parenteral labetalol or oral nifedipine were preferable first line agents in accordance with association of intravenous hydralazine with more maternal and perinatal adverse effects, such as maternal hypotension, maternal oliguria, cesarean section, placental abruption, adverse effects on fetal heart rate and low Apgar scores at one minute $[36,56]$.

Isosorbide nitrate, a nitric oxid (NO) donor, has been investigated in a small study of gestational hypertensive and preeclamptic pregnant patients. It was found that cerebral perfusion pressure is unaltered by isosorbide dinitrate, despite significant changes in maternal BP, thus decreasing the risk for ischemia and infarction when BP is lowered [57].

Sodium nitroprusside and diazoxide are known to produce precipitous falls in blood pressure, often with adverse effects in an already compromised fetus [58]. Sodium nitroprusside, a direct NO donor, which non-selectively relaxes both arteriolar and venular vascular smooth muscle, is potent, rapid-acting and short-lasting drug which is used in pregnancy for the treatment of an acute hypertensive crisis not responding to other agents. Administered only by continuous titrated because it has a nearimmediate onset of action and duration of effect of 3 minutes. Considering that utilization of this medication may cause fetus cyanide poisoning, transient fetal bradycardia, metabolic acidosis, and maternal hypotension, it must be given under continuous surveillance and with caution. When control of acute crisis is attained, the fetus should be delivered as soon as possible. It is a drug of last choice for the treatment of acute hypertension in pregnancy.

\section{Diuretics}

Diuretics are commonly orally administrated antihypertensives in non pregnant patients because of low cost and suitable impact on major cardiovascular events as shown in randomized controlled trials. Although diuretics reducing maternal plasma volume have been reported to be connected with poor perinatal outcome, negative effect on fetal growth has not been completely proven. It does not seem to increase neonatal thrombocytopenia or other adverse effect among newborns. Hydrochlorothiazide, triamterene and amiloride are not considered teratogenic [59-61]. The use of spironolactone is not advised because of its antiandrogenic effects during fetal development [62,63]. Given their apparent safety, the National High Blood Pressure Education Program Working Group on High Blood Pressure in Pregnancy concluded that they may be continued through gestation (with an attempt made to lower the dose) or used in combination with other agents, especially for women deemed likely to have salt-sensi- 
tive hypertension. Hydrochlorothiazide may be continued during pregnancy: the use of low doses (12.5 to $25 \mathrm{mg}$ daily) may minimize untoward metabolic effects, such as impaired glucose tolerance and hypokalemia [18]. Mild volume contraction with diuretic therapy may lead to hyperuricemia and in so doing invalidate serum uric acid levels as a laboratory marker in the diagnosis of superimposed preeclampsia. Women with chronic hypertension, who, before conception, respond well to a thiazide diuretic, could have a drug reinstituted in pregnancy but it should be withdrawn if preeclampsia develops [64].

Angiotensin-converting-enzyme inhibitors and angiotensin receptor antagonists

Angiotensin-converting-enzyme (ACE) inhibitors are widely prescribed and well tolerated antihypertensives, but are contraindicated in second and third trimesters because of toxicity associated with reduced fetal renal perfusion. It is proved that it may cause oligohydramnios as a result of fetal oliguria, fetal growth restriction, calvarial and pulmonary hypoplasia, joint contractures and renal dysgenesis, neonatal anuric renal failure, hypotension, and death $[65,66]$. Similar fetal anomalies have been reported after treatment of women in the second or third trimesters of pregnancy with angiotensin II receptor antagonists [67], attributed primarily to renal failure $[68,69]$. The abnormalities are probably related to fetus sensibility to the hypotensive action of these drugs: the pharmacological suppression of the fetal rennin-angiotensin system seems to dis- rupt fetal vascular perfusion and renal function.

Some studies have reported fetopathy among women who took ACE inhibitors only during the first trimester of pregnancy. Several studies have shown that the expression of the type II angiotensin receptor peaks early in gestation and then gradually declines, with a role in the early embryologic development of the heart, kidney and brain. These drugs have also been shown to inhibit the proliferation of fetal smooth-muscle cells in the ductus arteriosus, which may lead to patent ductus [70]. Cooper et al conducted a study to assess the association between exposure to ACE inhibitors during the first trimester and risk of congenital malformations. They followed 29.507 infants whose mothers had no evidence of diabetes: the risk of major malformations was higher in infants who had been exposed to ACE inhibitors, compared with infants who had not been exposed to antihypertensives (OR 2.71), while exposure to other antihypertensive medications did not increase the risk of major malformations. Among infants with exposure to ACE inhibitors in the first trimester alone, the adjusted proportion with any major congenital malformation was $7.1 \%$. ACE inhibitors increased risk of malformations of the cardiovascular system and the central nervous system [71]. It has also been suggested that these agents should be avoided by women who attempt to conceive [72]. Whether adverse outcomes are because of a hemodynamic effect in the fetus or specific requirements for angiotensin II as a fetal growth factor is unknown, yet first trimester use of these drugs should be avoided. Because angiotensin II receptors are widely expressed in fetal tissues and could have an important role in fetal development, it is possible that first trimester exposition to ACE inhibitors increases the risk of congenital malformations.

Because exposure to ACE inhibitors during first trimester is not considered safe, it may be best to counsel women to switch to alternative agents while attempting to conceive. In those who inadvertently become pregnant, the risk of birth defects rises from 3\% to 7\%. Pregnancy termination is not recommended. Direct rennin inhibitors might be expected to have similar effect as ACE-I and angiotensin receptor blocking agents in pregnancy, and should be avoided in this setting.

\section{Serotonin 2 receptor blockers}

Serotonin-induced vasodilatation is mediated by $\mathrm{S} 1$ receptors and release of prostacyclin and NO. Endothelial dysfunction and loss of endothelial S1 receptors allows serotonin, of which the levels are greatly increased in pregnancy, to react only with $\mathrm{S} 2$ receptors, resulting in vasoconstriction and platelet aggregation. Ketanserin is a selective S2 receptor-blocking drug that decreases systolic and diastolic BP in non pregnant patients with acute or chronic hypertension. It has not be found to be teratogenic in animals or humans and has been studied in small trials primarily in Australia and South Africa, which suggest that it may be safe and useful in the treatment of chronic hypertension in pregnancy, preeclampsia, and HELLP syndrome $[73,74]$. Ketanserin has not 


\section{OF alumeat rips}

Table 1. Antihypertensive drugs for chronic hypertension in pregnancy

\begin{tabular}{lll}
\hline Medication & Recommended Dose & Comments \\
\hline First line therapy & & \\
\hline Methyldopa & 0.5 to $3 \mathrm{~g} /$ day in 2 to 3 times & Most studied drug in pregnancy, can cause somnolence \\
\hline Labetalol & 200 to $1200 \mathrm{mg} /$ day in 2 to 3 times & \\
\hline Second/Third line therapy & & \\
\hline Hydralazine & 50 to $300 \mathrm{mg} /$ day in 2 to 4 times & Related to newborn thrombocytopenia \\
\hline Atenolol & 50 to $100 \mathrm{mg} /$ day in 2 to 3 times & Related to IUGR \\
\hline Nifedipine & 30 to $120 \mathrm{mg} /$ day in 3 to 4 times & Chronic use can cause headache \\
\hline Verapamil & 240 to $320 \mathrm{mg} /$ day in 3 times & Nauseas, dizziness, constipation \\
\hline Hydrochlorothiazide & 12.5 to $50 \mathrm{mg} /$ day in the morning & Related to hemorrhagic pancreatitis, thrombocytopenia, and sodium and kalium depletion in newborn \\
\hline
\end{tabular}

Adapted from Umans, Lindheimer 1998 and NHBPEP 2000

Table 2. Acute hypertension treatment $(\mathrm{BP}>155 / 105 \mathrm{~mm} \mathrm{Hg})$

-Woman lying on her left side

- Venous access with dextrose 5\%

- Options of treatment:

Nifedipine $10 \mathrm{mg}$, repeat every 30 minutes if necessary, in a total of $30 \mathrm{mg}$.

If no adequate response can be used endovenous hydralazine $5 \mathrm{mg}$ (diluting 1 ampoule $-2 \mathrm{ml} 20 \mathrm{mg}$ ) in $3 \mathrm{ml}$ of distilled water, each $1 \mathrm{ml}$ is $5 \mathrm{mg}$ of hydralazine). If blood pressure is not controlled, repeat 5 to $10 \mathrm{mg}$ every 20 minutes.

Repeat the medication if necessary until $30 \mathrm{mg}$ for each drug (BP $>155 / 105 \mathrm{~mm} \mathrm{Hg}$ ).

Also endovenous labetalol is an option: $20 \mathrm{mg}$ in bolus, and if necessary, repeat $40 \mathrm{mg}$ in 10 minutes and more two doses of $80 \mathrm{mg}$ every 10 minutes (total dose 220 $\mathrm{mg}$ ). Not recommended in asthmatic patients or with cardiac insufficiency.

- Maternal blood pressure measurement every 5 minutes for 20 minutes after medication.

- Fetal heart pattern evaluation by at least 20 minutes after the medication.

- BP targets $<160 / 110$ and $>135 / 85 \mathrm{~mm} \mathrm{Hg}$.

Adapted from NHBPEP 2000

been FDA approved for pregnancy in the United States.

\section{Management of hypertension postpartum}

In the postpartum period, previously normotensive women have been noted to have a rise in BP, which reaches a maximum on the fifth postpartum day: $12 \%$ of the patients present a $\mathrm{DBP}>100$ $\mathrm{mm} \mathrm{Hg} \mathrm{[75].} \mathrm{This} \mathrm{occurs} \mathrm{as} \mathrm{a} \mathrm{conse-}$ quence of physiological volume expansion and fluid mobilization in the postpartum period. The natural history of gestational hypertension and preeclampsia in the postpartum period and the maximum time to normalization (beyond which chronic hypertension should be diagnosed) are not known. As noted in a recent Cochrane review, the need for treatment, the management of antihypertensive drugs and patient counseling with respect to postpartum has been unguided by the literature [76]. However, it was suggested that treatment should be initiated if the BP exceeds $150 \mathrm{~mm} \mathrm{Hg}$ of systolic or $100 \mathrm{~mm} \mathrm{Hg}$ of diastolic in the first 4 days of the puerperium [77].
Choice of antihypertensive agent in the postpartum period is often influenced by breastfeeding, but in general the agents commonly used in the antepartum period may be continued postpartum. The medication may be discontinued when BP normalizes, which occurs days to several weeks postpartum, and home BP monitoring may be helpful.

In cases of severe preeclampsia, oral furosemide seems to be benefiting a brief course in the days postpartum, particularly in cases of hypertension with symptomatic pulmonary or peripheral 
edema [78]. Case reports have suggested that nonsteroidal anti-inflammatories may contribute to BP elevation postpartum, and the effects on non pregnant individuals are well documented [79]. These drugs should be used with caution or perhaps be avoided in postpartum patients already hypertensive.

There are no well-designed studies assessing neonatal effects of maternally administered antihypertensive drugs delivered via breast milk. Neonatal exposure to methyldopa via nursing is likely low, and it is generally considered safe. Atenolol and metoprolol are concentrated in breast milk, possibly to levels that could affect the infant. By contrast, exposure to labetalol and propranolol seems low. Although milk concentration of diuretics is low and considered safe, these agents can decrease milk production significantly. There are reports of calcium channel blockers transfer into breast milk, apparently without adverse effects. Sufficient data exist for the safety of captopril and enalapril [80].

\section{Summary}

For severe hypertension, antihypertensive medication is used to prevent serious maternal and fetal complications. However, there is no consensus on when to treat mild-to-moderate hypertension. Although treatment could benefit the mother, it carries potential risks to the fetus from impaired uteroplacental perfusion and fetal exposure to medication. Acceptable agents include methyldopa, labetalol and nifedipine in standard doses. Atenolol use should be avoided in pregnancy, because it has been associated with lower birth weights. ACE-Is and angiotensin receptor blockers should be avoided in all trimesters. Control of severe hypertension has been studied: intravenous labetalol or oral nifedipine is as effective as intravenous hydralazine, with fewer adverse effects.

A number of drugs have been used for long term treatment of hypertension in pregnancy. The most widely used are methyldopa and the beta-blockers, atenolol and labetalol. Methyldopa has been used extensively and appears to be effective and safe, for mother and fetus. Maternal side effects include lethargy, drowsiness and depression, and drug induced hepatitis can be confused with early HELLP syndrome. Although betablockers are considered safe in pregnancy, intrauterine growth restriction has been linked to their use and side effects of hypoglycemia and blockade of the neonatal cardiac conducting system have been reported.

Many research questions surrounding hypertension in pregnancy and preeclampsia remain unanswered, needing large studies. Currently guidelines are based on small trials and expert opinion. Future studies should determine fetal and maternal outcomes. A review from WHO Reproductive Health Library, including 46 trials involving 4282 women, do not have sufficient data for most of the outcomes, and large multicenter randomized controlled trials on the impact of blood pressure treatment on substantive health outcomes are needed [14].

As women in developed countries delay childbirth, the impact of chronic hypertension will increase. Clinicians do not have sufficient evidence to know which pharmacological is best, when to begin treatment, how vigorously to treat, or whether to stop treatment and hope that the hypotensive effect of normal pregnancy will be enough to control blood pressure [81]. The only trial of treatment of hypertension during pregnancy with adequate infant followup (7.5 years) was performed over 25 years ago with a drug (methyldopa) now rarely used in non pregnant patients. Past clinical trials also have not supported a beneficial effect on pregnancy outcome of treating mild hypertension, with no reduction in perinatal mortality, placental abruption or superimposed preeclampsia. All these trials are subject to criticism, including small numbers, starting the drug too late in pregnancy, or flawed study design. Because of the unknown long term effects on the infants of any treatment, these studies have lead to recommendations to treat only on the basis of blood pressure elevated to pose potential acute risk to the mother. Even for women with blood pressure elevation sufficient to justify therapy for their own benefit, it is not clear whether treatment is beneficial or detrimental for the fetus. In several studies, treatment of hypertensive women resulted in an increased risk of growth restriction in their infants. It is not known whether this is the consequence of lowering blood pressure during pregnancy or it is due to excessive blood pressure decreases or specific drugs.

Dietary and other lifestyle changes have been shown in non pregnant women to lower blood pressure in the short term. In the Dietary Approaches to Stop Hypertension (DASH)-Sodium Study, the combination of DAS diet and lower 
sodium intake reduced SBP by $11.5 \mathrm{~mm}$ $\mathrm{Hg}$ over 4 weeks. Whether such blood pressure reduction can be achieved safely in hypertensive pregnant women is not known and should be evaluated [82].

The ideal drug for the treatment of pregnancy hypertension should be rapidly effective and long acting, with minimal side effects to the mother, and it should not compromise the fetus either directly or by a reduction in placental perfusion. The objective of treating hypertension in pregnancy is to protect the women from dangerously high blood pressure and to permit continuation of the pregnancy, fetal growth and maturation.

\section{Conflict of interest}

The authors declare no conflict of interest.

\section{References}

1. Magee LA, Ornstein MP, von Dadelszen P. Fortnightly review: management of hypertension in pregnancy. BMJ 1999;318:1332-6.

2. Davis GK, Mackenzie C, Brown MA, Homer CS, Holt J, McHugh L. Predicting transformation from gestational hypertension to preeclampsia in clinical practice: a possible role for 24 hour ambulatory blood pressure monitoring. Hypertens Pregnancy 2007;26(1):77-87.

3. Barton JR, O'Brien JM, Bergauer NK, Jacques DL, Sibai BM. Mild gestational hypertension remote from term: progression and outcome. Am J Obstet Gynecol 2001;184:979-83.

4. Sibai BM. Chronic hypertension in pregnancy. Obstet Gynecol 2002;100(2):369-77.

5. Folic M, Folic N, Varjacic M, Jakovijevic M, Jankovic S. Antihypertensive drug therapy for hypertensive disorders in pregnancy. Acta Medica Medianae 2008;47(3):65-72.
6. James PR, Nelson-Piercy C. Management of hypertension before, during and after pregnancy. Heart 2004;90(12):1499-504.

7. Sibai BM, Abdella TN, Anderson GD. Pregnancy outcome in 211 patients with mild chronic hypertension. Obstet Gynecol 1983;61:571.

8. Abalos E, Duley L, Steyn D, Henderson-Smart D. Antihypertensive drug therapy for mild to moderate hypertension during pregnancy. Cochrane Database Syst Rev 2007;CD002252.

9. Levine RJ, Maynard SE, Qian C, Lim KH, England LJ, Yu KF. Circulating angiogenic factors and the risk of preeclampsia. N Engl J Med 2004;350:672-83.

10. Report of the national high blood pressure education program working group on high blood pressure in pregnancy. Am J Obstet Gynecol 2000;183:S1S22.

11. Sibai BM. Diagnosis and management of gestational hypertension and preeclampsia. Obstet Gynecol 2003;102:181-92.

12. Sibai BM. Chronic hypertension in pregnancy. Clin Perinatol 1991;18:83344.

13. Montán S. Drugs used in hypertensive diseases in pregnancy. Curr Opin Obstet Gynecol 2004;16(2):111-5.

14. Lubano K, Qureshi Z. Antihypertensive drug therapy for mild-to-moderate hypertension during pregnancy. RHL commentary 2007. The WHO Reproductive Health Library. Geneva: World Health Organization.

15. Sibai BM. Treatment of hypertension in pregnancy. $\mathrm{N}$ Engl $\mathrm{J}$ Med 1996;335:257-65.

16. Duley L, Henderson-Smart DJ, Meher S. Drugs for treatment of very high blood pressure during pregnancy. Editorial Group: Cochrane Pregnancy and Childbirth Group. The Cochrane Library 2012;CD001449.

17. von Dadelszen P, Magee LA. Antihy- pertensive medications in management of gestational hypertension-preeclampsia. Clin Obstet Gynecol 2005;48:44159.

18. Magee LA. Drugs in pregnancy. Antihypertensives. Best Pract Res Clin Obstet Gynaecol 2001;15:827-45.

19. Butters L, Kennedy S, Rubin PC. Atenolol in essential hypertension in pregnancy. BMJ 1990;301:587-9.

20. Rey E, LeLorier J, Burgess E, Lange IR, Leduc L. Report of the Canadian Hypertension Society consensus conference. Pharmacologic treatment of hypertensive disorders in pregnancy. Can Med Assoc J 1997;157:1245-54.

21. Brown MA, Hague WM, Higgins J, Lowe S, McCowan L, Oats J. The detection, investigation and management of hypertension in pregnancy: full consensus statement. Aust N Z J Obstet Gynaecol 2000;40:139-55.

22. Sibai BM, Barton JR. Expectant management of severe preeclampsia remote from term: patient selection, treatment, and delivery indications. Am J Obstet Gynecol 2007;196:514.

23. Martin JN, Thigpen BD, Moore RC, Rose $\mathrm{CH}$, Cushman J, May W. Stroke and severe preeclampsia and eclampsia: a paradigm shift focusing on systolic blood pressure. Obstet Gynecol 2005;105:246-54

24. Schardein JL. Chemically induced birth defects. 3rd ed. New York: Marcel Dekker, Inc; 2000.

25. Caton AR, Bell EM, Druschel CM, Werler MM, Lin AE, Browne ML. Antihypertensive medication use during pregnancy and the risk of cardiovascular malformations. Hypertension 2009;54:63-70.

26. Fidler J, Smith V, Fayers P. Randomised controlled comparative study of methyldopa and oxprenolol in treatment of hypertension in pregnancy. BMJ 1983;286:1927-30.

27. Ounsted MK, Moar VA, Good FJ, Redman CW. Hypertension during pregnan- 
cy with and without specific treatment; the development of the children at the age of four years. Br J Obstet Gyneacol 1980;87:19-24.

28. Podymow T, August P. Update on the use of antihypertensive drugs in pregnancy. Hypertension 2008;51:960-9.

29. Khedun S, Maharaj B, Moodley J. Effects of antihypertensive drugs on the unborn child. Paediatr Drugs 2000;2(6):419-36.

30. Wide-Swensson D, Montan S, Arulkumaran S, Ingemarsson I, Ratnam SS. Effect of methyldopa and isradipine on fetal heart rate pattern assessed by computerized cardiotocography in human pregnancy. Am J Obstet Gynaecol 1993;169:1581-5.

31. Sibai BA, Mabie WC, Shamsa F, Villar MA, Anderson GD. A comparison of no medication versus methyldopa or labetalol in chronic hypertension during pregnancy. Am J Obstet Gynaecol 1990;162:960-7.

32. Redman CW, Beilin LJ, Bonnar J. Treatment of hypertension with methyldopa blood pressure control and side effects. BJOG 1977;84:419-26.

33. Cockburn J, Moar VA, Ounsted M, Redman CW. Final report of study on hypertension during pregnancy: the effects of specific treatment on the growth and development of the children. Lancet 1982;319:647-9.

34. von Dadelszen P, Ornstein MP, Bull SB, Logan AG, Koren G, Magee LA. Fall in mean arterial pressure and fetal growth restriction in pregnancy hypertension. Lancet 2000;355:87-92.

35. Sibai BM, Gonzalez AR, Mabie WC, Moretti M. A comparison of labetalol plus hospitalization versus hospitalization alone in the management of preeclampsia remote from term. Obstet Gynecol 1987;70:323-7.

36. Magee LA, Cham C, Waterman EJ, Ohlsson A, von Dadelszen. Hydralazine for treatment of severe hypertension in pregnancy: meta-analysis. BMJ
2003;327:955-60.

37. Pasker-de Jong PC, Zielhuis GA, van Gelder MM, Pellegrino A, Gabreëls FJ, Eskes TK. Antihypertensive treatment during pregnancy and functional development at primary school age in a historical cohort study. BJOG 2010;117:1080-6.

38. Bayliss h, Churchill D, Beevers M, Beevers DG. Antihypertensive drugs in pregnancy and fetal growth: evidence for "pharmacological programming" in the first trimester? Hypertens Pregnancy 2002;21:161-74.

39. Magee LA, Duley L. Oral beta-blockers for mild to moderate hypertension during pregnancy. Cochrane Database Syst Rev 2000;CD002863.

40. Waterman EJ, Magee LA, Lim KI, Skoll A, Rurak D, von Dadelszen P. Do commonly used oral antihypertensives alter fetal or neonatal heart rate characteristics? A systematic review. Hypertens Pregnancy 2004;23:155-69.

41. Grodski S, Jung C, Kertes P, Davies M, Banting S. Phaeochromocytoma in pregnancy. Intern Med J 2006;36:6046.

42. Bartels PA, Hanff LM, Mathot RAA, Steegers EAP, PA Bartels, Vulto AG, et al. Nicardipine in preeclamptic patients: placental transfer and disposition in breast milk. BJOG 2007;114:230-3.

43. Wide-Swensson DH, Ingemarsson I, Lunell NO, Forman A, Skajaa K, Lindberg B. Cacium channel blockade (isradipine) in treatment of hypertension in pregnancy: a randomized placebocontrolled study. Am J Obstet Gynecol 1995; 173:872-8.

44. Casele HL, Windley KC, Prieto JA, Gratton R, Laifer SA. Felodipine use in pregnancy. Report of three cases. J Reprod Med 1997;42:378-81.

45. Belfort MA, Anthony J, BUccimazza A, Davey DA. Hemodynamic changes associated with intravenous infusion of the calcium antagonist verapamil in the treatment of severe gestational pro- teinuric hypertension. Obstet Gynecol 1990;75:970-4.

46. Brown MA, Buddle ML, Farrel T, Davis GK. Efficacy and safety of nifedipine tablets for the acute treatment of severe hypertension in pregnancy. Am J Obstet Gynecol 2002;187:1046-50.

47. Prevost RR, Pharm D, Sherif A, Whybrew DW, Sibai BM. Oral nifedipine: pharmacokinetics in pregnancy induced hypertension. Pharmacotherapy 1992;12:174-7.

48. Smith P, Anthony J, Johanson R. Nifedipine in pregnancy. BJOG 2000;107:299-307.

49. Magee LA, Miremadi S, Li J, Cheng C, Ensom MH, Carleton B. Therapy with both magnesium sulphate and nifedipine does not increase the risk of serious magnesium-related maternal side effects in women with preeclampsia. Am J Obstet Gynecol 2005;193:153-63.

50. Papatsonis DN, Lok CA, Bos JM, Geijn HP, Dekker GA. Calcium channel blockers in the management of preterm labor and hypertension in pregnancy. Eur J Obstet Gynecol Reprod Biol 2001;97:122-40.

51. Magee LA, Schick B, Donnenfeld AE, Sage SR, Conover B, Cook L. The safety of calcium channel blockers in human pregnancy: a prospective, multicenter cohort study. Am J Obstet Gynecol 1996;174:823-8.

52. Aya AGM, Mangin R, Hoffet M, Eledjam JJ. Intravenous nicardipine for severe hypertension in preeclampsia, effects of an acute treatment on mother and fetus. Intensive Care Med 1999;25:1277-81.

53. Elatrous S, Nouira S, Ouanes Besbes L, S. Marghli, M. Boussarssar, M. Sakkouhi. Short-term treatment of severe hypertension of pregnancy: prospective comparison of nicardipine and labetalol. Intensive Care Med 2002;28:1281-6.

54. Task Force on the Management of Cardiovascular Diseases during Pregnancy 
of the European Society of Cardiology. Expert consensus document on management of cardiovascular diseases during pregnancy. Eur Heart J 2003;24:761-81.

55. Widerlov E, Karlman I, Storsaret J. Hydralazine-induced neonatal thrombocytopenia. N Engl J Med 1980;303:1235.

56. Magee LA, Abalos E, von Dadelszen P, Sibai B, Walkinshaw SA. CHIPS Study Group. Control of hypertension in pregnancy. Curr Hypertens Rep 2009;11(6): 429-36.

57. Nevo O, Thaler I, Shik V, Vortman T, Soustiel JF. The effect of isosorbide dinitrate, a donor of nitric oxide, on maternal cerebral blood flow in gestational hypertension and preeclampsia. Am J Obstet Gynecol 2003;188:1360-5.

58. Godlin RC. Fetal and maternal effects of sodium nitroprusside. Am J Obstet Gynaecol 1983;146:350-1.

59. Sibai BM, Grossman RA, Grossman HG. Effects of diuretics on plasma volume in pregnancies with long-term hypertension. Am J Obstet Gynaecol 1984;150:831-5.

60. Collins R, Yusuf S and Peto R. Overview of randomized trials of diuretics in pregnancy. BMJ 1985;290:17-23.

61. Psaty BM, Smith NL, Siscovick DS, Koepsell TD, Weiss NS, Heckbert SR. Health outcomes associated with antihypertensive therapies used as first-line agents: a systematic review and metaanalysis. JAMA 1997;277:739-45.

62. Groves TD, Corenblum B. Spironolactone therapy during human pregnancy. Am J Obstet Gynaecol 1995;172:16556.

63. Gress TW, Nieto J, Shahar E, Wofford MR, Brancati FL. Hypertension and antihypertensive therapy as risk factors for type 2 diabetes mellitus. N Engl J Med 2000;342:905-12.

64. Chambers JC, Fusi L, Malik IS, Haskard DO, De Swiet M, Kooner JS. Association of maternal endothelial dysfunction with preeclampsia. JAMA 2001;285:1607-12.
65. Quan A. Fetopathy associated with exposure to angiotensin converting enzyme inhibitors and angiotensin receptor antagonists. Early Hum Dev 2006;82:23-8.

66. Pryde PG, Sedman AB, Nugent CE, Barr M. Angiotensin-converting enzyme inhibitor fetopathy. J Am Soc Nephrol 1993;3:1575-82.

67. Alwan S, Polifka JE, Friedman JM. Angiotensin II receptor antagonist treatment during pregnancy. Birth Defects Res A Clin Mol Teratol 2005;73:12330.

68. Briggs GG, Nageotte MP. Fatal fetal outcome with the combined use of valsartan and atenolol. Ann Pharmacolther 2001;35:859-61.

69. Lambot MA, Vermeylen D, Noel JC. Angiotensin-II-receptor inhibitors in pregnancy. Lancet 2001;357:1619-20.

70. Steffensen FH, Nielsen GL, Sørensen HT, Olesen C, Olsen J. Pregnancy outcome with ACE-inhibitors use in early pregnancy. Lancet 1998;351(9102):596.

71. Cooper WO, Hernandez-Diaz S, Arbogast PG, Dudley JA, Dyer S, Gideon PS. Major congenital malformations after first-trimester exposure to ACE inhibitors. N Engl J Med 2006;354:243351.

72. Bos-Thompson MA, Hillaire-Buys D, Muller F, Dechaud H, Mazurier E, Boulot P. Fetal toxic effects of angiotensin II receptor antagonists: case report and follow-up after birth. Ann Pharmacother 2005;39(1):157-61.

73. Bolte AC, van Geijn HP, Dekker GA. Pharmacological treatment of severe hypertension in pregnancy and the role of serotonine(2)-receptor blockers. Eur J Obstet Gynecol Reprod Biol 2001;95:22-36.

74. Steyn DW, Odendaal HJ. Serotonin antagonism and serotonin antagonists in pregnancy: role of ketanserin. Obstet Gynecol Surv 2000;55:582-9.

75. Widerlov E, Karlman I, Storsater J. Hydralazine-induced neonatal thrombocy- topenia. N Engl J Med 1980;303:1235.

76. Magee L, Sadeghi S. Prevention and treatment of postpartum hypertension. Cochrane Database Syst Rev 2005;CD004351.

77. Tan LK, de Swiet M. The management of postpartum hypertension. BJOG 2002;109:733-6.

78. Ascarelli MH, Johnson V, McCreary H, Cushman J, May WL, Martin JN Jr. Postpartum preeclampsia management with furosemide: a randomized clinical trial. Obstet Gynecol 2005;105:29-33.

79. Makris A, Thornton C, Hennessy A. Postpartum hypertension and non-steroidal analgesia. Am J Obstet Gynecol 2004;190:577-8.

80. Transfer of drugs and other chemicals into human milk. American Academy of Pediatrics Committee on Drugs. Pediatrics 2001;108:776-89.

81. Roberts JM, Pearson G, Cutler J, Lindheimer M. Summary of the NHLBI Working Group on Reseach on Hypertension during Pregnancy. Hypertension 2003;41:437-45.

82. Sacks FM, Svetkey LP, Vollmer WM, Appel LJ, Bray GA, Harsha D. Effects on blood pressure of reduced dietary sodium and the Dietary Approaches to Stop Hypertension (DASH) diet: DASH-Sodium Collaborative Research Group. N Eng J Med 2001;344:3-10. 